\title{
Efficiency of an electronic device in controlling tracheal cuff pressure in critically ill patients: a randomized controlled crossover study
}

\author{
Anahita Rouzé1, Julien De Jonckheere ${ }^{2}$, Farid Zerimech³ ${ }^{3}$ Julien Labreuche ${ }^{4}$, Erika Parmentier-Decrucq ${ }^{1}$, \\ Benoit Voisin' ${ }^{1}$ Emmanuelle Jaillette ${ }^{1}$, Patrice Maboudou ${ }^{3}$, Malika Balduyck ${ }^{3,5}$ and Saad Nseir ${ }^{1,6^{*}}$
}

\begin{abstract}
Background: Despite intermittent control of tracheal cuff pressure $\left(P_{\text {cuff }}\right)$ using a manual manometer, cuff underinflation $\left(<20 \mathrm{cmH}_{2} \mathrm{O}\right)$ and overinflation $\left(>30 \mathrm{cmH}_{2} \mathrm{O}\right)$ frequently occur in intubated critically ill patients, resulting in increased risk of microaspiration and tracheal ischemic lesions. The primary objective of our study was to determine the efficiency of an electronic device in continuously controlling $P_{\text {cuff. }}$. The secondary objective was to determine the impact of this device on the occurrence of microaspiration of gastric or oropharyngeal secretions.

Methods: Eighteen patients requiring mechanical ventilation were included in this prospective randomized controlled crossover study. They randomly received either continuous control of $P_{\text {cuff }}$ with Mallinckrodt ${ }^{\circledR}$ device for $24 \mathrm{~h}$, followed by discontinuous control with a manual manometer for $24 \mathrm{~h}$, or the reverse sequence. During the $48 \mathrm{~h}$ after randomization, $P_{\text {cuff }}$ was continuously recorded, and pepsin and alpha amylase were quantitatively measured in tracheal aspirates. $P_{\text {cuff }}$ target was $25 \mathrm{cmH}_{2} \mathrm{O}$.

Results: Clinical characteristics were similar during the two study periods, as well as mean airway pressure. Percentage of time spent with cuff overinflation or underinflation was significantly lower during continuous control compared with routine care period [median (IQR) $0.8(0.1,2)$ vs $20.9(3.1,40.1), p=0.0009$ ]. No significant difference was found in pepsin [median (IQR) $230(151,300)$ vs $259(134,368), p=0.95$ ] or in alpha amylase level [median (IQR) 1475 $(528,10,333)$ vs $2400(1342,15,391), p=0.19]$ between continuous control and routine care periods, respectively.

Conclusions: The electronic device is efficient in controlling $P_{\text {cuff, }}$ compared with routine care using a manometer. Further studies are needed to evaluate the impact of this device on intubation-related complications.

Trial registration ClinicalTrials.gov Identifier: NCT01965821
\end{abstract}

Keywords: Tracheal cuff, Intubation, Mechanical ventilation, Complications, Microaspiration

\section{Background}

In spite of the increased use of noninvasive ventilation and high-flow nasal oxygen [1-3], intubation is still frequently performed in up to $85 \%$ of critically ill patients requiring mechanical ventilation [4]. This invasive procedure is associated with several potential complications,

\footnotetext{
${ }^{*}$ Correspondence: s-nseir@chru-lille.fr

${ }^{1}$ Centre de Réanimation, CHU Lille, 59000 Lille, France

Full list of author information is available at the end of the article
}

such as microaspiration of contaminated oropharyngeal and gastric secretions, ventilator-associated pneumonia, and tracheal ischemic lesions [5-10]. These intubationrelated complications occur when tracheal cuff is inadequately inflated [11].

Current recommendations are to keep cuff pressure $\left(P_{\text {cuff }}\right)$ between 20 and $30 \mathrm{cmH}_{2} \mathrm{O}$, using a manometer [12]. Unfortunately, these recommendations are not followed in a high percentage of ICUs [13]. Even 
when tracheal cuff is routinely monitored and adjusted by nurses, patients spend a large amount of time up to 30-50 \% outside the targeted range [14-18]. Moreover, $P_{\text {cuff }}$ drops under $20 \mathrm{cmH}_{2} \mathrm{O}$ each time the manometer is connected [19]. Several new devices are available to continuously control $P_{\text {cuff }}$ and prevent complications related to underinflation or overinflation of tracheal cuff [2022]. Although many devices are available on the market, few of them were evaluated and validated by well-conducted clinical studies. These devices could be classified into mechanical and electronic. The advantages in using an electronic device are its easy use and the lower cost, compared with a pneumatic device.

The efficiency of the electronic device was evaluated in one in vitro study [23]. However, to our knowledge no clinical randomized controlled study has evaluated the efficiency of the electronic device in critically ill patients receiving mechanical ventilation for more than $48 \mathrm{~h}$. Therefore, we conducted this randomized controlled trial to determine the efficiency of the electronic device in continuously controlling $P_{\text {cuff }}$. The secondary objective of this study was to evaluate the impact of continuous control of $P_{\text {cuff, }}$ using the electronic device, on microaspiration of gastric contents in intubated critically ill patients.

\section{Methods}

This prospective randomized controlled crossover study was performed during a 1 -year period, in a 10-bed ICU at the university hospital of Lille (France), in accordance with the Helsinki Declaration.

\section{Inclusion and exclusion criteria}

Inclusion criteria were: age $>18$ years and mechanical ventilation through a tracheal tube for a predicted duration of at least $48 \mathrm{~h}$. Exclusion criteria were: mechanical ventilation through a tracheostomy, enrollment in another study that might interfere with the current study results, pregnancy, and contraindication for enteral nutrition.

\section{Randomization}

Patients were randomly assigned to receive continuous control of $P_{\text {cuff }}$ with the electronic device (Mallinckrodt electronic cuff pressure controller ${ }^{\circledR}$, VBM Medizintechnik GmbH, Sulz am Neckar, Germany) for $24 \mathrm{~h}$, followed by discontinuous control (every $8 \mathrm{~h}$ ) with a manual manometer (Hi-Lo Hand Pressure Gauge ${ }^{\circledR}$, Mallinckrodt, Medtronic TM) for $24 \mathrm{~h}$ (Fig. 1), or the reverse sequence (Fig. 2). The target of $P_{\text {cuff }}$ was $25 \mathrm{cmH}_{2} \mathrm{O}$ during the two periods. Randomization was performed using a computer-generated random assignment list in balanced blocs of six. Treatment assignments were contained in sealed opaque envelopes sequentially numbered.

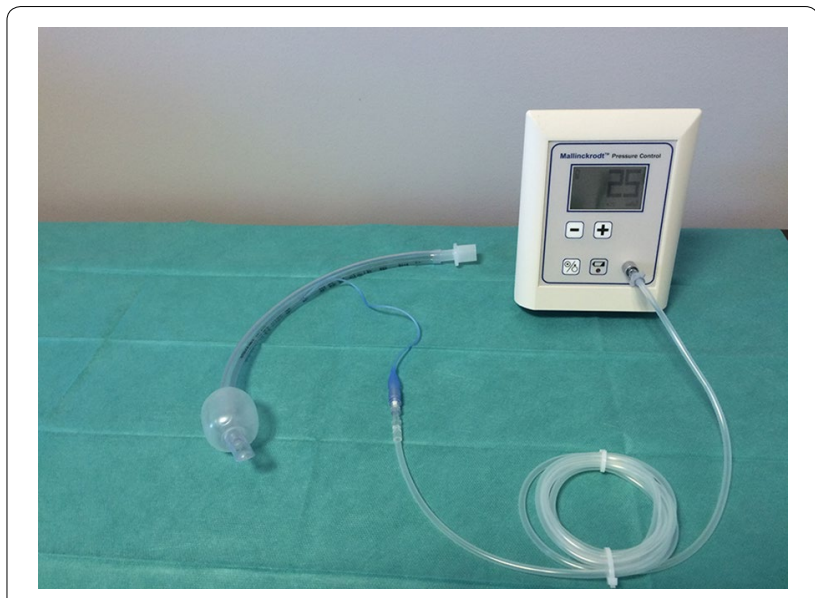

Fig. 1 Electronic device connected to a tracheal tube

\section{Study objectives and outcome measurement}

The primary objective was to determine the efficiency of the electronic device in reducing percentage of time spent with underinflation or overinflation of tracheal cuff, compared with routine care using a manometer. The secondary objectives included the impact of the electronic device on percentage of patients with underinflation or overinflation of tracheal cuff, percentage of time spent with underinflation of tracheal cuff, percentage of time spent with overinflation of tracheal cuff, percentage of time spent with normal $\left(20-30 \mathrm{cmH}_{2} \mathrm{O}\right)$ tracheal cuff, $P_{\text {cuff, }}$ and coefficient of variation of $P_{\text {cuff, }}$ compared with routine care, and its impact on microaspiration of gastric and oropharyngeal secretions.

$P_{\text {cuff }}$ and airway pressure were continuously recorded at a digitizing frequency of $100 \mathrm{~Hz}$ for $48 \mathrm{~h}$ (Physiotrace ${ }^{\circledR}$; Estaris, Lille, France) [24], including $24 \mathrm{~h}$ of continuous control of $P_{\text {cuff }}$ using the mechanical device and $24 \mathrm{~h}$ of manual control of $P_{\text {cuff }}$ using the manometer (Fig. 3). Pepsin and alpha amylase were quantitatively measured in all tracheal aspirates during the two study periods $[25,26]$. In order to avoid interference between the two periods regarding pepsin and alpha amylase levels, tracheal aspirate performed during the first $2 \mathrm{~h}$ of each study period was not analyzed. The engineer who analyzed the data (JDJ) and the physicians who measured pepsin and alpha amylase (FZ, $\mathrm{PM}$, and $\mathrm{MB}$ ) were blinded to study group assignment.

\section{Study population}

All patients were intubated with a high-volume low-pressure PVC standard-cuffed tracheal tube. Tracheal tube size was 8 and 7.5 in men and women, respectively. During the manometer period, nurses adjusted $P_{\text {cuff }}$ every $8 \mathrm{~h}$. Tracheal suctioning was performed, using open suction system, 6 times a day, or more frequently if clinically indicated. 


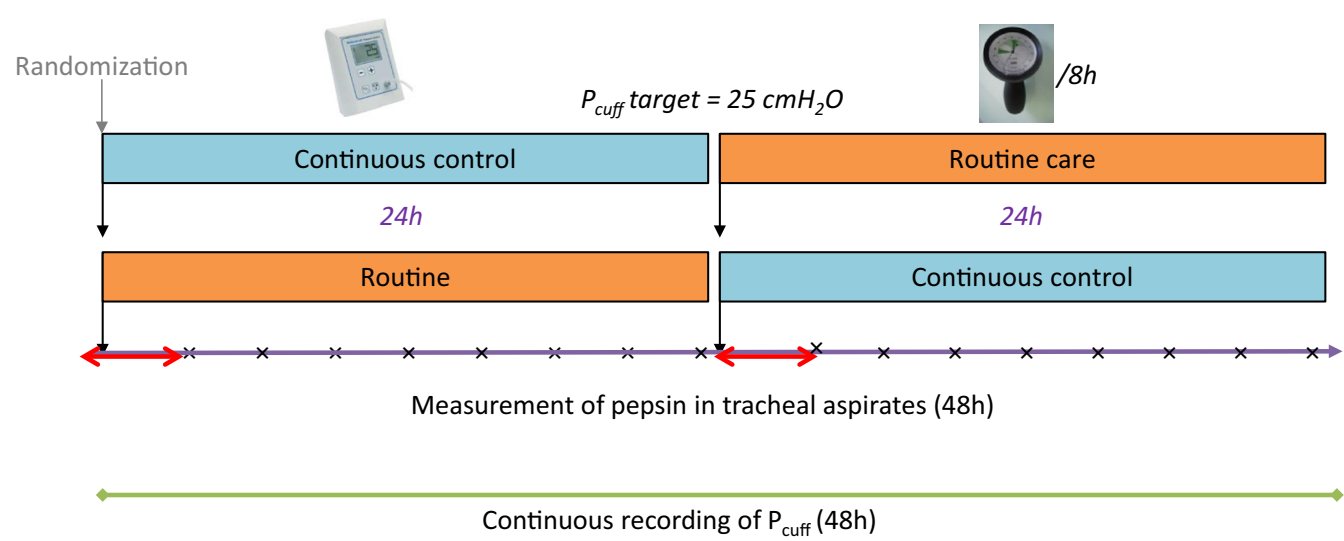

Fig. 2 Study design. Red arrows indicate washout periods for pepsin and amylase measurement, and times symbol indicates each tracheal aspirate performed for pepsin and amylase measurement

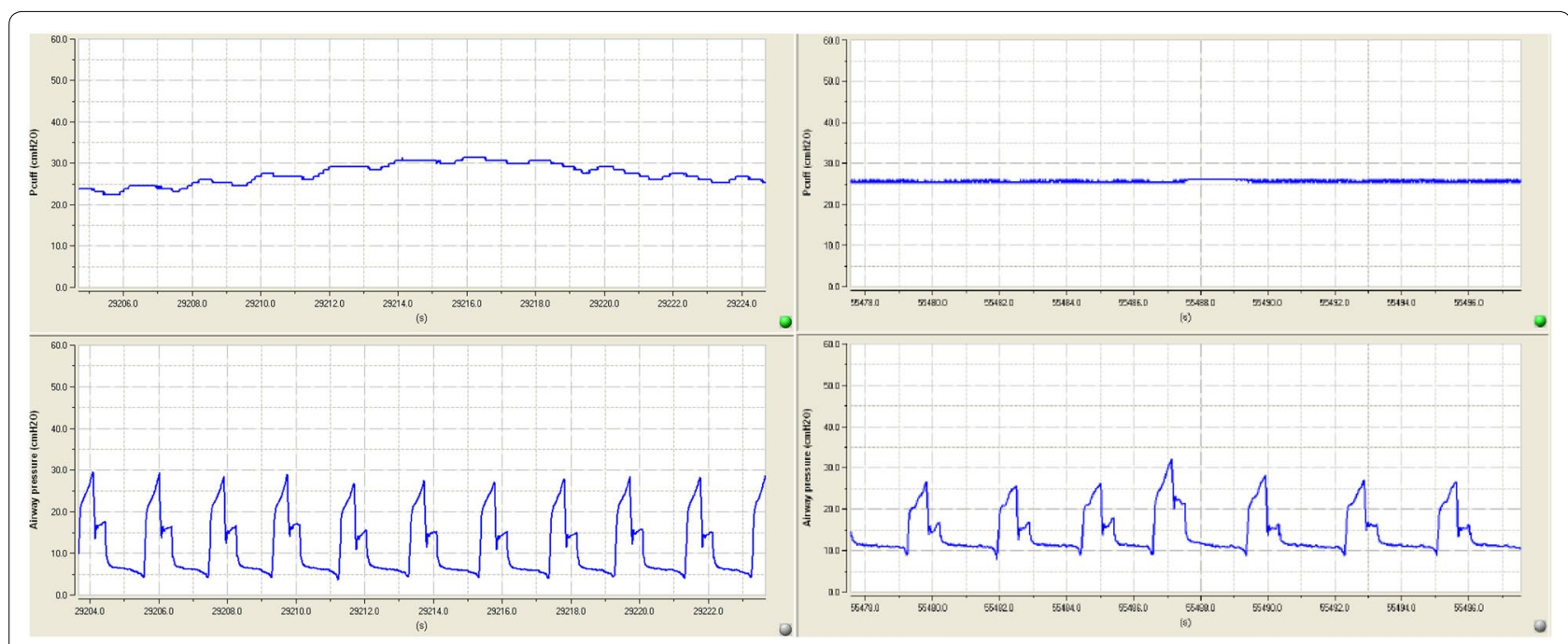

Fig. 3 An example of cuff and airway pressure recording. At left, cuff pressure (above), and airway pressure (below), during routine care. At right, cuff pressure (above) and airway pressure (below) during continuous control of cuff pressure

Semi-recumbent position was used during mechanical ventilation. During routine care period, $P_{\text {cuff }}$ was adjusted, using the manometer, before turning and oral care.

\section{Definitions}

The primary outcome was the percentage of time spent with underinflation or with overinflation of tracheal cuff. Secondary outcomes included mean $P_{\text {cuff, }}$ coefficient of variation of $P_{\text {cuff, }}$ percentage of patients with underinflation of tracheal cuff, percentage of patients with overinflation of tracheal cuff, percentage of time spent with normal $\left(20-30 \mathrm{cmH}_{2} \mathrm{O}\right)$ cuff pressure, percentage of time spent with underinflation of tracheal cuff, percentage of time spent with overinflation of tracheal cuff, mean pepsin and alpha amylase level, percentage of tracheal aspirates positive for pepsin, and percentage of tracheal aspirates positive for alpha amylase.

Underinflation of tracheal cuff was defined as $P_{\text {cuff }}$ $<20 \mathrm{cmH}_{2} \mathrm{O}$ for $>5$ min over the 24-h period of recording. Overinflation of tracheal cuff was defined as $P_{\text {cuff }}$ $>30 \mathrm{cmH}_{2} \mathrm{O}$ for $>5$ min over the 24 -h period of recording [14]. The coefficient of variation of $P_{\text {cuff }}$ was calculated as standard deviation/mean $P_{\text {cuff }} \times 100$.

Microaspiration of gastric contents was defined by the presence of pepsin at significant level $(>200 \mathrm{ng} / \mathrm{mL})$ in tracheal aspirate. Microaspiration of oropharyngeal secretions was defined by the presence of alpha amylase at significant level (>1685 UI/L) in tracheal aspirate [26]. 


\section{Statistical analyses \\ Sample size calculation}

Based on previous results $[14,15]$, the mean percentage of time spent with underinflation or overinflation of tracheal cuff was $30 \%$ [standard deviation (SD) $=20 \%$ ] in patients intubated with a PVC-cuffed tracheal tube receiving routine care of $P_{\text {cuff }}$ using a manual manometer. The expected mean percentage of time with underinflation or overinflation of tracheal cuff using the mechanical device was $10 \%$ (expected difference of $20 \%$ ). In a parallel-group design, $n=22$ patients per group will be required to detect this difference with a two-sided test, a power of $90 \%$, an alpha risk of $5 \%$, and a SD of $20 \%$. In a crossover design, the sample size determination is based on SD within subject difference, which can be derived from SD of measure and coefficient correlation $(r)$ between the two measures on the same subject [27]. The sample size can therefore be derived from the number of patients to be included in parallel-group design, as follows: $n *(1-r)$. Thus, assuming a conservative value of 0.2 for $r$, the number of patients to include is 18 .

\section{Result analysis}

All analyses were performed in an intention-to-treat manner. Distribution of quantitative variables was tested using Shapiro-Wilk test. Normally and non-normally distributed variables were expressed as mean \pm SD and median (25th, 75th interquartile), respectively. The statistical significance was set at $p<0.05$.

The primary outcome was compared using a mixed linear model, adjusting for the period effect. Interaction between study period and assigned treatment, i.e., continuous control of $P_{\text {cuff }}$ or routine care, was tested. Qualitative and quantitative patient characteristics and secondary outcomes were compared between the two 24-h periods using McNemar and Wilcoxon tests, respectively.

\section{Results}

During the study period, 23 patients were eligible. Five patients were excluded for different reasons, and 18 patients were included and were all analyzed (Fig. 4).

\section{Patient characteristics}

Patient characteristics are presented in Table 1.

No significant difference was found between the two study periods regarding ventilator mode and settings, sedation, Ramsay score, or neuromuscular blocking agent use. Prone position was not used in included patients, during the two study periods. All other characteristics were also similar during the two periods (Table 2).

No significant difference was found in duration of $P_{\text {cuff }}$ and airway pressure recording [median (IQR) 23 (23, 23.3 vs $23.5 \mathrm{~h}(23,24), p=0.066]$, or in mean airway pressure $\left[13.2(10.7,15.5)\right.$ vs $\left.13.1 \mathrm{cmH}_{2} \mathrm{O}(10.8,15.6)\right]$ between continuous control and routine care periods, respectively.

\section{Primary outcome}

The percentage of time spent with underinflation, or with overinflation, was significantly lower during continuous control of $P_{\text {cuff }}$ compared with routine care [median (IQR) $0.8(0.1,2)$ vs $20.9(3.1,40.1), p=0.0009]$. No significant interaction was found between study period and the assigned treatment $(p=0.91)$.

\section{Secondary outcomes}

Mean $P_{\text {cuff }}$ and percentage of time spent with $P_{\text {cuff }}$ 20-30 $\mathrm{cmH}_{2} \mathrm{O}$ were significantly higher during continuous control of $P_{\text {cuff }}$ compared with routine care. Percentage of patients with underinflation, percentage of time spent with underinflation, percentage of time spent with overinflation, and coefficient of variation of $P_{\text {cuff }}$ were significantly lower during continuous control compared with routine care of tracheal cuff. Percentage of patients with overinflation was similar during the two study periods (Table 3).

No significant difference was found in pepsin level, in percentage of tracheal aspirates positive for pepsin, in alpha amylase level, or in percentage of tracheal aspirates positive for alpha amylase between the two study periods (Table 3).

\section{Discussion}

Our results suggest that the electronic device is efficient in controlling $P_{\text {cuff }}$. However, no significant impact of continuous control of $P_{\text {cuff }}$ was found on microaspiration of gastric or oropharyngeal secretions.

To our knowledge, our study is the first clinical randomized controlled study to evaluate the efficiency of the electronic device in continuously controlling $P_{\text {cuff }}$ in critically ill patients. A previous in vitro study found similar results [23]. In addition, Lorente et al. [28] conducted a prospective observational study to determine the impact of continuous control of $P_{\text {cuff }}$, using the same electronic device, on the incidence of VAP. The authors reported significantly lower rate of $P_{\text {cuff }}$ determinations $<20 \mathrm{cmH}_{2} \mathrm{O}$ (mean \pm SD 0 vs $9 \pm 8, p<0.001$ ), $P_{\text {cuff }}$ determinations $>30 \mathrm{cmH}_{2} \mathrm{O}$ (mean $\pm \mathrm{SD} 0$ vs $4 \pm 5, p<0.001$ ), and substantial decrease (51\%) in VAP incidence in patients who received continuous control of $P_{\text {cuff }}$, compared with those received routine care. However, the efficiency of the electronic device in continuously controlling $P_{\text {cuff }}$ was not the primary objective of the study. In addition, $P_{\text {cuff }}$ was not continuously recorded, and the study was not randomized.

The percentage of time spent with underinflation (median $9.1 \%$ ) and with overinflation (median $2.4 \%$ ) 


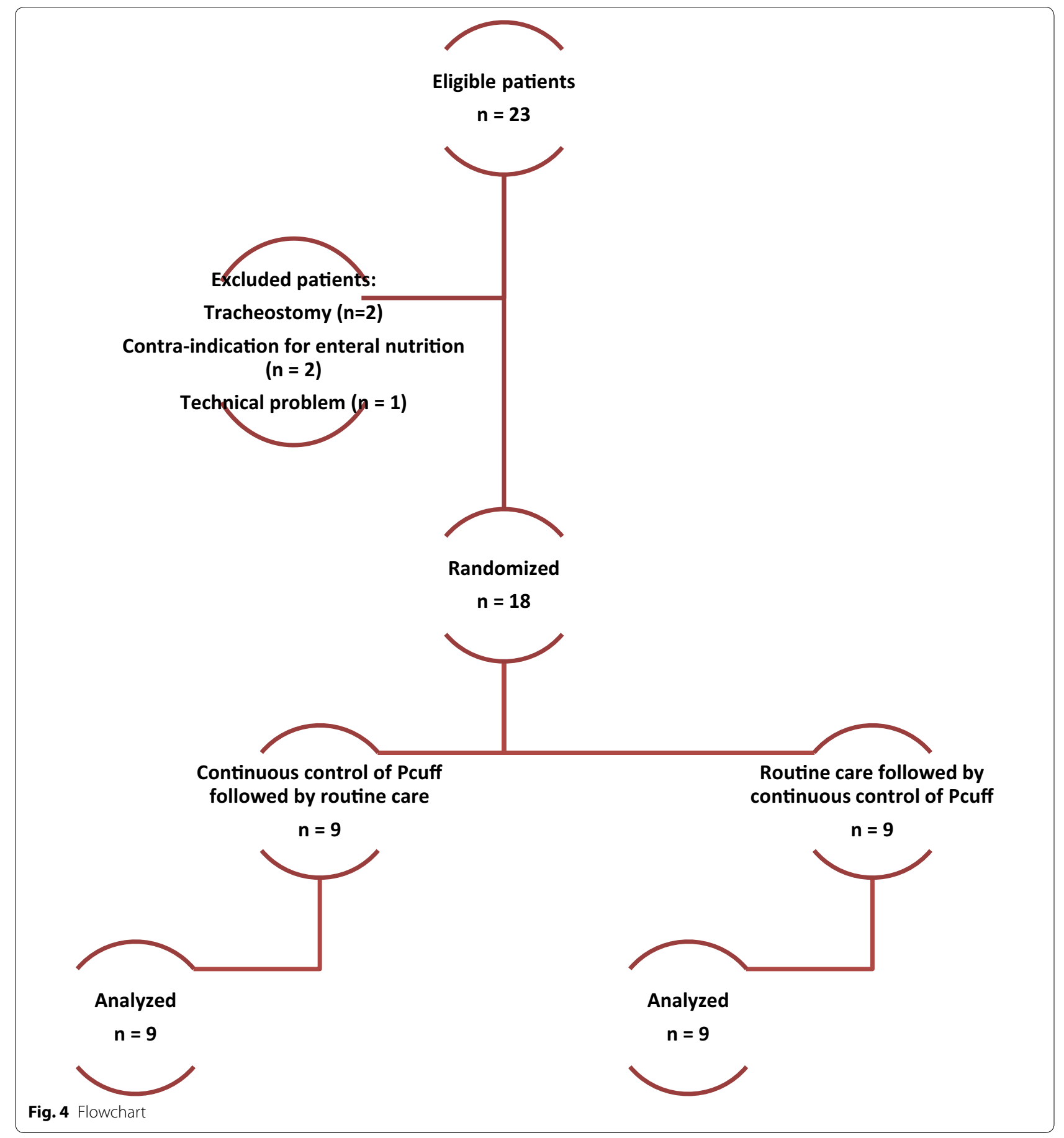

during routine care was lower than previously reported $[14,15]$. The small number of patients included in the current study $(n=18)$ could explain this difference. Duration of prior intubation was identified as an independent risk factor for underinflation of tracheal cuff [14]. However, duration of prior intubation was quite similar in the current study (median 4 days) compared with previous studies
(2 and 5 days, respectively) $[14,15]$. Another explanation could be the different patient characteristics between the current study and previous ones. The percentage of nonsedated patients was lower in the current study (22\%) compared with the two previous ones ( 35 and $53 \%$, respectively). The absence of sedation was identified as an independent risk factor for underinflation of tracheal cuff [14]. 


\section{Table 1 Patient characteristics}

\begin{tabular}{ll}
\hline Number of included patients & 18 \\
Age (years), mean \pm SD & $54 \pm 18$ \\
Male gender, $n$ (\%) & $13(72)$ \\
Weight (kg), median (IQR) & $72(66,81)$ \\
SAPS II, mean \pm SD & $43 \pm 16$ \\
LOD score, mean \pm SD & $6 \pm 3$ \\
Cause for ICU admission, $n$ 5\% & \\
$\quad$ Neurologic failure & $7(38)$ \\
Respiratory failure & $6(33)$ \\
$\quad$ Shock & $5(27)$ \\
Duration of mechanical ventilation before inclusion (days), & $4(2,6)$ \\
$\quad$ median (IQR) & $12(7,25)$ \\
Total duration of mechanical ventilation (days), median (IQR) & $21(11,30)$ \\
Length of ICU stay (days), median (IQR) & $3(15)$ \\
Ventilator-associated pneumonia, $n$ (\%) & $10(55)$ \\
ICU mortality, $n$ (\%) &
\end{tabular}

SAPS Simplified Acute Physiology Score, LOD logistic organ dysfunction, IQR interquartile range

No significant impact of continuous control of $P_{\text {cuff }}$ was found on microaspiration of gastric and oropharyngeal secretions. Several explanations could be suggested for this finding. Microaspiration of gastric contents was a secondary outcome, and our study was probably underpowered to detect such an effect. The higher, but not significant, level of alpha amylase during continuous control, compared with routine care periods, is in keeping with this hypothesis. Although this secondary outcome was negative, the results could be helpful for future studies, aiming at evaluating the impact of continuous control of $P_{\text {cuff }}$ on microaspiration. In addition, the duration of tracheal aspirate collection $(24 \mathrm{~h})$ during the two study periods was probably too short to evaluate this effect. Further, the above-mentioned in vitro study reported that the electronic device might interfere with self-expanding properties of some PVC-cuffed tracheal tubes [23]. Therefore, the rapid correction of overinflation of $P_{\text {cuff }}$ during cough could result in short sudden drop of $P_{\text {cuff }}$ and microaspiration of gastric contents. Further studies are needed to confirm this hypothesis. The short washout period $(2 \mathrm{~h})$ used in this study might have resulted in overlap in pepsin and alpha amylase results between the two periods. Whilst pepsin half-life is relatively short [29], alpha amylase half-life is unknown. This might have influenced the impact of continuous control of $P_{\text {cuff }}$ on microaspiration of gastric and oropharyngeal secretions.

Table 2 Patient characteristics during the $48 \mathrm{~h}$ following randomization

\begin{tabular}{|c|c|c|c|}
\hline Variables & $\begin{array}{l}\text { Continuous control of } P_{\text {cuff }} \\
n=18\end{array}$ & $\begin{array}{l}\text { Routine care } \\
n=18\end{array}$ & $\mathrm{p}$ \\
\hline Ventilatory mode ${ }^{a}$ & & & $>0.99$ \\
\hline ACV & $13(72)$ & $13(72)$ & \\
\hline PSV & $9(50)$ & $10(56)$ & \\
\hline Mean $P_{\text {peak }}\left(\mathrm{cmH}_{2} \mathrm{O}\right)$ & $31(21,35)$ & $30(24,34)$ & 0.64 \\
\hline Mean PEEP $\left(\mathrm{cmH}_{2} \mathrm{O}\right)$ & $7(5,9)$ & $6(5,8)$ & 0.73 \\
\hline Mean $\mathrm{FiO}_{2}$ & $0.45(0.40,0.50)$ & $0.40(0.40,0.50)$ & 0.41 \\
\hline Number of tracheal suctions & $6(5,7)$ & $6(6,7)$ & $>0.99$ \\
\hline Sedation & $12(67)$ & $14(78)$ & 0.50 \\
\hline Ramsay score & $5(3,6)$ & $4(3,6)$ & 0.86 \\
\hline Neuromuscular blocking agent use & $1(6)$ & $0(0)$ & $>0.99$ \\
\hline Head-of-bed position $<30^{\circ}$ & $4(22)$ & $6(33)$ & 0.50 \\
\hline Fiberoptic bronchoscopy & $2(11)$ & $2(11)$ & $>0.99$ \\
\hline Transport outside the ICU & $0(0)$ & $1(6)$ & $>0.99$ \\
\hline Aerosolized medication & $2(11)$ & $2(11)$ & $>0.99$ \\
\hline ¡NO & $2(11)$ & $1(6)$ & $>0.99$ \\
\hline Quantity of enteral nutrition (mL/day) & $1000(500,1500)$ & $1000(875,1125)$ & 0.31 \\
\hline Gastric residual volume $(\mathrm{mL})$ & $0(0,61)$ & $0(0,100)$ & 0.52 \\
\hline Vomiting & $2(11)$ & $2(11)$ & $>0.99$ \\
\hline Prokinetic drugs & $1(6)$ & $1(6)$ & $>0.99$ \\
\hline Stress ulcer prophylaxis or treatment & $16(89)$ & $16(89)$ & $>0.99$ \\
\hline
\end{tabular}

Data are number of patients (\%) or median (Interquartile range)

$P_{\text {cuff }}$ cuff pressure, $A C V$ assist-control ventilation, $P S V$ pressure support ventilation, $P_{\text {peak }}$ peak pressure, $P E E P$ positive end-expiratory pressure, $F i O_{2}$ fraction of inspired oxygen, $i$ O inhaled nitric oxide

a Some patients received two ventilator modes during continuous control of $P_{\text {cuff, }}$ or during routine care 
Table 3 Secondary outcomes

\begin{tabular}{|c|c|c|c|}
\hline Variables & $\begin{array}{l}\text { Continuous control } \\
n=18\end{array}$ & $\begin{array}{l}\text { Routine care } \\
n=18\end{array}$ & $p$ \\
\hline Mean $P_{\text {cuff }}\left(\mathrm{cmH}_{2} \mathrm{O}\right)$ & $25.9(25.5,26.4)$ & $22.7(21.6,24.8)$ & 0.001 \\
\hline Coefficient of $P_{\text {cuff }}$ variation (\%) & $4.1(1.5,6.1)$ & $7.7(4.4,11.5)$ & $<0.001$ \\
\hline \multicolumn{4}{|l|}{$P_{\text {cuff }} 20-30 \mathrm{cmH}_{2} \mathrm{O}$} \\
\hline Yes & $18(100)$ & $18(100)$ & $>0.99$ \\
\hline$\%$ of recording time & $99.1(97.9,99.9)$ & $73.5(54.4-96.8)$ & $<0.001$ \\
\hline \multicolumn{4}{|l|}{$P_{\text {cuff }}<20 \mathrm{cmH}_{2} \mathrm{O}$} \\
\hline Yes & $0(0)$ & $13(72)$ & $<0.001$ \\
\hline$\%$ of recording time & $0.0(0,0)$ & $9.1(0.0-36.1)$ & 0.001 \\
\hline \multicolumn{4}{|l|}{$P_{\text {cuff }}>30 \mathrm{cmH}_{2} \mathrm{O}$} \\
\hline Yes & $11(61)$ & $14(78)$ & 0.25 \\
\hline$\%$ of recording time & $0.8(0.1,2.1)$ & $2.4(0.7,9.4)$ & $<0.001$ \\
\hline Pepsin $(n g / m L)$ & $230(151,300)$ & $259(134,369)$ & 0.95 \\
\hline$\%$ of tracheal aspirates positive for pepsin & $67(0,100)$ & $71(0,100)$ & 0.83 \\
\hline Alpha amylase $(\mathrm{ng} / \mathrm{mL})$ & $1475(528,10,333)$ & $2400(1342-15,391)$ & 0.19 \\
\hline$\%$ of tracheal aspirates positive for alpha amylase & $40(0,100)$ & $33(0,100)$ & 0.92 \\
\hline
\end{tabular}

Data are number of patients (\%) or median (interquartile range)

$P_{\text {cuff }}$ cuff pressure

Yes indicates that a patient had the variable at least once

Given the efficiency of the electronic device, the absence of potential harm, and the reduction in nurse workload, one could argue that use of such a device could be recommended in every intubated critically ill patient. However, the level of evidence on the clinical benefit of using continuous control of $P_{\text {cuff }}$ is still low [30]. In addition, cost-effectiveness of this preventive measure of VAP was not evaluated. Therefore, further randomized controlled trials aiming at evaluating the impact of continuous control of $P_{\text {cuff }}$ on VAP incidence are required to evaluate the efficiency of this preventive measure.

Some limitations of our study should be acknowledged. First, this was a single-center study. Therefore, our results could not be generalized to patients hospitalized in other ICUs. We did not evaluate the impact of continuous control of $P_{\text {cuff }}$ using the electronic device on ventilatorassociated pneumonia or tracheal ischemic lesions. However, our study design did not allow such an evaluation, because each patient was his own control. This design is probably the best first step to evaluate the efficiency of the electronic device, because of potential patient-related confounders, such as tracheal size, shape, respiratory resistance, and airway pressure. Further, the study was not blinded. However, investigators who assessed continuous $P_{\text {cuff }}$ recording and pepsin were blinded to study group assignment.

\section{Conclusions}

The electronic device evaluated in this study is efficient in continuously controlling $P_{\text {cuff }}$ in critically ill patients. Further randomized controlled studies are needed to determine the impact of continuous control of $P_{\text {cuff }}$ using the electronic device, on intubation-related complications, such as microaspiration, VAP, and tracheal ischemia.

\section{Abbreviations \\ $P_{\text {cuff: }}$ cuff pressure; SAPS: Simplified Acute Physiology Score; LOD: logistic organ dysfunction.}

\section{Authors' contributions}

$A R$, JDJ, MB, FZ, and SN designed the study. AR, JDJ, EP, BV, EJ, FZ, and PM collected data. JL and SN performed statistical analysis. AR and SN wrote the manuscript. All authors participated in the final revision of the manuscript and approved the submitted version. All authors read and approved the final manuscript.

\section{Author details}

${ }^{1}$ Centre de Réanimation, CHU Lille, 59000 Lille, France. ${ }^{2}$ Centre d'Investigation Clinique, CHU Lille, 59000 Lille, France. ${ }^{3}$ Centre de Biologie et de Pathologie, CHU Lille, 59000 Lille, France. ${ }^{4}$ EA 2694 - Santé publique : épidémiologie et qualité des soins, CHU Lille, 59000 Lille, France. ${ }^{5}$ Faculté de Pharmacie, Université Lille, 59000 Lille, France. ${ }^{6}$ Faculté de Médecine, Université Lille, 59000 Lille, France.

\section{Acknowledgements}

None.

\section{Competing interests}

SN received fees from Medtronic for lecture, and from Ciel Medical for advisory board. AR, JDJ, FZ, JL, EP, BV, EJ, PM and MB: none. 


\section{Availability of data and material}

All data are available in the manuscript.

\section{Ethic approval and consent to participate}

The institutional review board of the Lille University Hospital (Comité de Protection des Personnes Nord-Ouest IV) approved the study (No. 2013A0022540). Written consent was obtained from the patients or from their next of kin (ClinicalTrials.gov Identifier: NCT01965821).

Received: 11 August 2016 Accepted: 29 September 2016 Published online: 04 October 2016

\section{References}

1. Papazian L, Corley A, Hess D, Fraser JF, Frat J-P, et al. Use of high-flow nasal cannula oxygenation in ICU adults: a narrative review. Intensive Care Med. 2016;42:1336-49

2. Cabrini L, Landoni G, Oriani A, Plumari VP, Nobile L, et al. Noninvasive ventilation and survival in acute care settings: a comprehensive systematic review and metaanalysis of randomized controlled trials. Crit Care Med. 2015:43:880-8.

3. Martinez-Urbistondo D, Alegre F, Carmona-Torre F, Huerta A, FernandezRos $\mathrm{N}$, et al. Mortality prediction in patients undergoing non-invasive ventilation in intermediate care. PLoS One. 2015;10:e0139702.

4. Esteban A, Frutos-Vivar F, Muriel A, Ferguson ND, Peñuelas O, et al. Evolution of mortality over time in patients receiving mechanical ventilation. Am J Respir Crit Care Med. 2013;188:220-30.

5. Nseir S, Zerimech F, Jaillette E, Artru F, Balduyck M. Microaspiration in intubated critically ill patients: diagnosis and prevention. Infect Disord Drug Targets. 2011;11:413-23.

6. Touat L, Fournier C, Ramon P, Salleron J, Durocher A, et al. Intubationrelated tracheal ischemic lesions: incidence, risk factors, and outcome. Intensive Care Med. 2013;39:575-82.

7. Blot SI, Poelaert J, Kollef M. How to avoid microaspiration? A key element for the prevention of ventilator-associated pneumonia in intubated ICU patients. BMC Infect Dis. 2014:14:119.

8. Branson RD, Gomaa D, Rodriquez D. Management of the artificial airway. Respir Care. 2014:59:974-89 (discussion 989-990)

9. Carter EL, Duguid A, Ercole A, Matta B, Burnstein RM, et al. Strategies to prevent ventilation-associated pneumonia: the effect of cuff pressure monitoring techniques and tracheal tube type on aspiration of subglottic secretions: an in vitro study. Eur J Anaesthesiol. 2014;31:166-71.

10. Blot SI, Rello J, Koulenti D. The value of polyurethane-cuffed endotracheal tubes to reduce microaspiration and intubation-related pneumonia: a systematic review of laboratory and clinical studies. Crit Care. 2016;20:203.

11. Jaillette E, Martin-Loeches I, Artigas A, Nseir S. Optimal care and design of the tracheal cuff in the critically ill patient. Ann Intensive Care. 2014:4:7.

12. American Thoracic Society, Infectious Diseases Society of America. Guidelines for the management of adults with hospital-acquired, ventilatorassociated, and healthcare-associated pneumonia. Am J Respir Crit Care Med 2005;171:388-16.

13. Talekar CR, Udy AA, Boots RJ, Lipman J, Cook D. Tracheal cuff pressure monitoring in the ICU: a literature review and survey of current practice in Queensland. Anaesth Intensive Care. 2014:42:761-70.
14. Nseir S, Brisson H, Marquette C-H, Chaud P, Di Pompeo C, et al. Variations in endotracheal cuff pressure in intubated critically ill patients: prevalence and risk factors. Eur J Anaesthesiol. 2009;26:229-34

15. Nseir S, Zerimech F, De Jonckheere J, Alves I, Balduyck M, et al. Impact of polyurethane on variations in tracheal cuff pressure in critically ill patients: a prospective observational study. Intensive Care Med. 2010:36:1156-63.

16. Lizy C, Swinnen W, Labeau S, Poelaert J, Vogelaers D, et al. Cuff pressure of endotracheal tubes after changes in body position in critically ill patients treated with mechanical ventilation. Am J Crit Care. 2014;23:e1-8.

17. Geng G, Hu J, Huang S. The effect of endotracheal tube cuff pressure change during gynecological laparoscopic surgery on postoperative sore throat: a control study. J Clin Monit Comput. 2015;29:141-4.

18. Lou Sole M, Su X, Talbert S, Penoyer DA, Kalita S, et al. Evaluation of an intervention to maintain endotracheal tube cuff pressure within therapeutic range. Am J Crit Care. 2011;20:109-18.

19. Farré $R$, Rotger $M$, Ferrer $M$, Torres $A$, Navajas D. Automatic regulation of the cuff pressure in endotracheally-intubated patients. Eur Respir J. 2002;20:1010-3.

20. Duguet A, D'Amico L, Biondi G, Prodanovic H, Gonzalez-Bermejo J, et al. Control of tracheal cuff pressure: a pilot study using a pneumatic device. Intensive Care Med. 2007:33:128-32.

21. Nseir S, Rodriguez A, Saludes P, De Jonckheere J, Valles J, et al. Efficiency of a mechanical device in controlling tracheal cuff pressure in intubated critically ill patients: a randomized controlled study. Ann Intensive Care. 2015:5:54.

22. Chenelle CT, Oto J, Sulemanji D, Fisher DF, Kacmarek RM. Evaluation of an automated endotracheal tube cuff controller during simulated mechanical ventilation. Respir Care. 2015;60:183-90.

23. Weiss M, Doell C, Koepfer N, Madjdpour C, Woitzek K, et al. Rapid pressure compensation by automated cuff pressure controllers worsens sealing in tracheal tubes. Br J Anaesth. 2009;102:273-8.

24. De Jonckheere J, Logier R, Dassonneville a, Delmar G, Vasseur C. PhysioTrace: an efficient toolkit for biomedical signal processing. In: Conference proceedings of the IEEE engineering in medicine and biology, vol. 7; 2005. p. 6739-41.

25. Nseir S, Zerimech F, Fournier C, Lubret R, Ramon P, et al. Continuous control of tracheal cuff pressure and microaspiration of gastric contents in critically ill patients. Am J Respir Crit Care Med. 2011;184:1041-7.

26. Dewavrin F, Zerimech F, Boyer A, Maboudou P, Balduyck M, et al. Accuracy of alpha amylase in diagnosing microaspiration in intubated critically-ill patients. PLoS One. 2014:9:e90851.

27. Julious SA. Sample sizes for clinical trials with normal data. Stat Med. 2004:23:1921-86.

28. Lorente L, Lecuona M, Jiménez A, Lorenzo L, Roca I, et al. Continuous endotracheal tube cuff pressure control system protects against ventilator-associated pneumonia. Crit Care. 2014;18:R77.

29. Metheny NA, Dahms TE, Chang Y-H, Stewart BJ, Frank PA, et al. Detection of pepsin in tracheal secretions after forced small-volume aspirations of gastric juice. JPEN J Parenter Enter Nutr. 2004;28:79-84.

30. Nseir S, Lorente L, Ferrer M, Rouzé A, Gonzalez O, et al. Continuous contro of tracheal cuff pressure for VAP prevention: a collaborative meta-analysis of individual participant data. Ann Intensive Care. 2015:5:43. 